\title{
DEMOCRACIA Y PARTICIPACIÓN EN JEAN-JACQUES ROUSSEAU*
}

\author{
Jorge Vergara Estévez \\ Universidad de Chile \\ vergaraestevez@gmail.com
}

\begin{abstract}
Resumen
Desde la publicación de El contrato social, en 1752, la concepción roussoniana de la democracia ha sido, de diversos modos, interpretada y cuestionada. Este artículo tiene una orientación hermenéutica: busca contribuir a esclarecerla y demostrar que las interpretaciones conservadoras que la identifican con el pensamiento autoritario e incluso totalitario no corresponden al sentido de los textos. Asimismo, se explicitan sus diferencias con las concepciones políticas de Hobbes y Locke. Podría decirse que Rousseau abre el espacio para el surgimiento de nuevas formas de pensamiento, respecto al liberalismo clásico y la Ilustración francesa. Fundó el pensamiento crítico sobre la sociedad moderna y planteó, lúcidamente, el problema de la fragmentación social y la necesidad de superarlo potenciando la dimensión comunitaria de la sociedad, mediante la constitución de un nuevo orden político y un nuevo proyecto educativo. Fundó, con ello, una nueva tradición democrática diferente a la de Locke: la concepción participativa de la democracia, basada en el principio de la soberanía popular, la cual ha alcanzado un importante desarrollo en nuestro tiempo.
\end{abstract}

PALABRAS ClaVE: democracia, soberanía popular, democracia representativa, democracia participativa, Estado.

\section{Abstract}

The Social Contract was first published in 1752. From then on, Rousseau's conception of democracy has been interpreted and questioned in several ways. This article has a hermeneutic approach, by trying to contribute to clarifying this conception and by proving that conservative interpretations identifying authoritarian or even totalitarian thinking with Rousseau's conceptions do not match with the sense of the texts. At the same time, Rousseau's differences with Hobbes and Locke's political conceptions are clearly set up. Otherwise, he anticipates the uprising of new forms of thinking regarding classic liberalism and the French Illustration. He generated critical thinking about modern society and clearly presented the problem of social fragmentation and the need to overcome this

Este artículo es una contribución al proyecto: "La articulación entre éticas del desarrollo y teorías democráticas participativas (deliberativas). Una investigación-reflexión", $\mathrm{N}^{\circ}$ 1120141 de FONDECYT, que estamos realizando con Raúl Villarroel del Departamento de Filosofía de la Universidad de Chile. Agradezco la revisión del texto de Marcos García de la Huerta, Director de esta publicación. En una futura versión querría incorporar la notable interpretación de Hermes Benítez de Rousseau como filósofo de la fragmentación social. 
by conferring power to the communitarian dimension of society, through the foundation of a new political order and a new educational project. The conception of participative democracy, based on the principle of popular sovereignty is the new democratic tradition founded by Rousseau, different from Locke's thinking. This conception has reached a important development in current times.

KEY WORDS: democracy, popular sovereignty, representative democracy, participative democracy, State.

\section{Rousseau, pensador de la democracia participativa}

"L'homme est né libre, et par-tout il est dans les fers. Je veux chercher si dans l'ordre civil il peut y avoir quelque regle d'administration légitime et sûre, en prenant les hommes tels qu'ils sont, et les loix telles qu'elles peuvent étre".

Jean- Jacques Rousseau, Du contrat social, Livre I

RA Pueden distinguirse dos períodos en su pensamiento. El primero se inicia con su primera obra, Discurso sobre las ciencias y las artes, de 1750, que cuestiona la concepción del progreso de los philosophes. En el Discurso sobre el origen y los fundamentos de la de la desigualdad, de 1755, plantea un esbozo de una filosofía de la historia y una crítica del absolutismo. En el Discurso sobre la economía política, de 1755, cuestiona las concepciones económicas de los enciclopedistas y de los fisiócratas. Y en el "Prefacio" de su obra de teatro Narcisse, de 1741, realizó una aguda crítica ética de la sociedad civil de su tiempo. La segunda fase comprende la publicación, en 1762, de sus obras principales: El contrato social y Emilio, que expresan su madurez filosófica.

Mediante sus análisis, Rousseau comprendió el carácter imperativo de las relaciones sociales y su poder para condicionar los fines y los medios de la conducta humana. En el Narciso mostró las conexiones entre las relaciones sociales y la moralidad. "Creo que se puede hacer una estimación muy justa de las costumbres de los hombres por la multitud de relaciones que tienen entre sí; cuanto más comercian entre ellos, más admiran sus talentos y sus habilidades (industrie), más se engañan decente y diestramente y más dignos son de desprecio. Lo digo con pesar; el hombre de bien no necesita engañar a nadie, y ese hombre es el salvaje"1 Posteriormente, destacó la importancia de las relaciones políticas para conformar y modificar a un pueblo. "Todo depende radicalmente de la política, y de cualquier modo que se obrase, ningún pueblo sería otra cosa que lo que le hiciera ser la naturaleza de su gobierno (forma de Estado)"2 
En los inicios de la Modernidad, Maquiavelo constató que las exigencias de la vida política imponen una conducta moral diferente a la privada, y consideró esta disociación propia de las épocas de crisis. Rousseau fue más allá examinando la disparidad entre el discurso ético y las prácticas sociales. La atribuye a las estructuras fundamentales de la sociedad moderna, a su forma de organización y no solo a situaciones de crisis. Esta disociación no podría resolverse mediante decisiones individuales aisladas. Se requiere transformar la sociedad para evitar que los hombres se vean obligados a hacer lo que no desean, y puedan hacer lo adecuado a su felicidad individual y la de todos.

Para Rousseau, la crisis de la sociedad moderna tenía, básicamente, carácter cultural y moral, y se expresaba a nivel político en el "despotismo", condensación de la crisis de su sociedad civil y de su moralidad. "De la extrema desigualdad de las condiciones y de la fortuna, de la diversidad de las pasiones y de los talentos, de las artes inútiles, de las artes perniciosas, de las ciencias frívolas saldrán infinidad de prejuicios, contrarios por igual a la razón, a la felicidad y a la virtud. Se verá a los jefes fomentar todo lo que pueda debilitar, desuniéndolos, a los hombres reunidos, todo lo que pueda dar a la sociedad un aire de concordia y sembrar en su seno un germen de división real, todo cuanto pueda inspirar a los diferentes órdenes recelo y odio mutuos mediante la oposición de sus derechos y sus intereses, y fortalecer por consiguiente el poder que a todos los contiene" 3 .

El despotismo constituiría la última fase del desarrollo histórico iniciado con la disolución del Estado patriarcal, el desarrollo de la técnica, el establecimiento de la propiedad y el surgimiento de la desigualdad entre los hombres ${ }^{4}$. Representa el cierre de un círculo histórico y una forma degradada de retorno al estado de naturaleza. "Aquí todos los individuos vuelven a ser iguales, puesto que son nada, y los súbditos no tienen otra ley que la voluntad del amo, y el amo no tiene otra norma que sus pasiones, las nociones del bien y los principios de la justicia se desvanecen de nuevo. Todo retorna a la ley del más fuerte y, por consiguiente, a un nuevo estado de naturaleza diferente del que comenzamos, que era el estado de naturaleza en su pureza, pues este último es el fruto de un exceso de corrupción" 5 .

Frente a la crisis multidimensional de la sociedad moderna, Rousseau propuso dos vías complementarias para superarla: la de la reforma educativa, en Emilio, y la refundación política, en El contrato social. Se expondrá ahora solo la segunda.

Rousseau plantea el problema político a nivel del interés. Si el despotismo representa la forma extrema de separación entre el interés de los gobernantes y de los

3 Rousseau, Jean-Jacques, "Discours sur l'origine...", OC, tomo III, 1964, p. 190. Me he basado en este párrafo en la traducción de Sebastián Masó en Rousseau, Escritos de combate, 1979, p. 206.

$4 \quad$ Rousseau, Jean-Jacques, "Discours sur l'origine...”, OC, tomo III, 1964, p. 190. (Cita de la traducción de este libro en Escritos de combate, Alfaguara, Madrid, 1979, p. 206).

5 Rousseau, Jean-Jacques, "Discours sur l'origine...”, $O C$, tomo III, 1964, p. 191 (Cita de la traducción de este libro en Escritos de combate, Alfaguara, Madrid, 1979, p. 207). 
gobernados, y la imposición del interés particular de los primeros sacrificando el de los segundos, la reforma deberá consistir en la reintegración de esta separación. En el Discurso de la desigualdad, escribía: "Hubiera querido nacer en un país donde el soberano y el pueblo no pudieran tener más que un solo y mismo interés, de modo que todos los movimientos de la máquina no se dirigieran a otro fin que el bien común".

Para Locke, la solución de este problema consistía en reservar el poder político a una clase social cuyos intereses particulares coincidieran con las de toda la sociedad, por tanto serían universales ${ }^{6}$. Rousseau rechaza este principio fundamental de la teoría del liberalismo clásico. Esto le permitió plantear una concepción participativa de la democracia, diferente de la de Locke y su concepción de la representación fundada en este supuesto. Su principio fundamental es que nadie puede representar al pueblo mejor que él mismo. Consecuentemente, su propuesta es hacer del pueblo el Soberano: "Y éste no podría hacerse a menos que el pueblo y el Soberano fueran una misma persona. Se desprende que yo hubiera querido nacer bajo un gobierno democrático prudentemente moderado" ".

La crítica del despotismo y de las formas no democráticas de gobierno está supuesta en El contrato social, desde sus primeras líneas: "L'homme né libre, et partout il est dans les fers" ${ }^{8}$. Esta oración combina dos enunciados diferentes. El primero afirma el carácter innato, natural, de la libertad humana y tiene carácter teórico. Su origen se remonta al derecho natural romano, que establecía que los hijos de padres libres lo eran por naturaleza ${ }^{9}$. La originalidad de Rousseau reside en otorgar a la libertad el carácter de esencia humana inalienable e irrenunciable. En el Discurso de la desigualdad escribía: "no es tanto el entendimiento lo que constituye la diferencia específica del hombre respecto a los animales, sino su cualidad de agente libre" ${ }^{10}$. En El contrato social dice "renunciar a la libertad es renunciar a la cualidad de hombre". Esta filosofía de la libertad es uno de los ejes centrales de constitución de su proyecto social y político. La segunda proposición es un enunciado fáctico que implica una interpretación crítica sobre los sistemas institucionales de la época ${ }^{11}$.

6 En la época se decía que lo que conviene a los comerciantes conviene a Inglaterra. Vd. Laski, Harold (1939), El liberalismo europeo.

Rousseau, Jean-Jacques, "Discours l'origine...", OC, tomo III, 1991, p. 112.

8 Rousseau, Jean-Jacques, "Du contrat social ou Principes de droit politique", $O C$, tomo III, 1991, p. 351.

$9 \quad$ El tema de la libertad, recuerda Hayek, aparece en el derecho romano como herencia. "El hombre, al menos el hombre europeo, entre en la historia dividido en libre y esclavo", en Hayek, Friedrich, Los fundamentos de la libertad, p. 33.

10 Rousseau, Jean-Jacques, "Discours sur l'origine", OC, tomo III, 1991, p. 141.

11 Rousseau, Jean-Jacques, "Du contrat social..., OC, tomo III, 1991, p. 356. Estas citas cuestionan la interpretación de Sabine que diferencian la tradición inglesa de la democracia fundada por Locke basada en la libertad, y la francesa inaugurada por Rousseau fundada en la igualdad. Vd. Sabine, George (1962). 
El contrato social supone también la crítica roussoniana de las relaciones de dominación. "Hay quienes se creen amo de los otros, pero no por ello deja de ser menos esclavo que ellos"12. Parece una paradoja: ¿Cómo podría decirse que el hombre que manda y es obedecido no es libre? Enunciados de esta naturaleza parecen justificar el reproche de "hombre paradojal" y "sofista", que sufrió en su época. En una de sus últimas obras, Cartas desde la montaña, ofrece una explicación esclarecedora. "La libertad consiste menos en hacer su voluntad que en no estar sometido a la de otro; consiste, también, en no someter la voluntad de otro a la nuestra. Quienquiera que sea amo no puede ser libre, pues reinar es obedecer"13. La libertad del amo es, pues, una ilusión. Los hombres han perdido para siempre su independencia natural. Su existencia se ha hecho social. "¿Cómo se produjo este cambio? Lo ignoro. ¿Qué puede legitimarlo? Creo poder resolver esta cuestión" 14 .

La primera pregunta es una cuestión histórica analizada en Discurso de la desigualdad, donde Rousseau explicita el carácter hipotético de su esbozo de desarrollo histórico universal, y no pretende descubrir las leyes de su desarrollo. En cambio, la pregunta de El contrato social es proyectiva: "Quiero investigar si en el orden civil puede haber alguna regla de administración legítima y segura, considerando a los hombres como son y a las leyes tal como pueden ser" ${ }^{15}$. Busca un principio que armonice la organización jurídica y política de la sociedad con la naturaleza humana. En otras palabras, busca reconstruir la sociedad a la medida del hombre. El principio buscado debe ser "legítimo" y "seguro". La primera exigencia se refiere a la libertad. Debe provenir de la libertad y preservarla; la segunda, puede ser entendida como certeza o como fuente de estabilidad y orden social.

Rousseau, a diferencia de sus contemporáneos, asumió la crisis de su tiempo y la incorporó en su horizonte de su reflexión. En el Emilio escribe: "nos aproximamos del estado de crisis, al siglo de la revoluciones". Allí advierte a un padre: "usted confía en el orden actual de la sociedad sin soñar que este orden está expuesto a revoluciones inevitables, y no puede prever, ni prevenir lo que puede aguardar a sus hijos". Agrega: "es del todo imposible que las grandes monarquías de Europa perduren todavía mucho tiempo" ${ }^{16}$. En este contexto de crisis de la sociedad moderna y del despotismo ilustrado, Rousseau presenta su proyecto orientado a la creación de un nuevo orden legítimo.

Consiguientemente, el objeto de El contrato social es la búsqueda de un principio de legitimación; es una investigación de teoría político-jurídica, no de historia política. Su subtítulo es "Principios de derecho político". En el Emilio señala que el derecho político no ha nacido aún, ni Hobbes ni Grocio pueden ser considerados sus fundadores.

12 Rousseau, Jean-Jacques, "Du contrat social..., OC, tomo III, 1991, p. 351.

13 Rousseau, Jean-Jacques, "Lettres écrites de la montagne”, $O C$, tomo III, 1991, pp. 842 y 843.

14 Rousseau, Jean-Jacques, "Lettres écrites de la montagne”, $O C$, tomo III, 1991, pp. 841 y 842.

15 Rousseau, Jean-Jacques, "Du contrat social”, $O C$, tomo III, 1991, p. 351.

16 Rousseau, Jean-Jacques, Emilio, (cit. por Kosselleck, Reinhart, Crítica y crisis del mundo burgués, 1965, pp. 287- 288). Este historiador de las ideas advierte que "el término "revolución" en el siglo XVIII era un concepto extra-político o supra-político, indirectamente político”, p. 288. 
Montesquieu hubiera podido serlo, pero se dedicó a estudiar el derecho positivo de los Estados, y "nada en el mundo hay más diferentes que estos dos estudios". El derecho político investiga los principios del mismo, que constituyen las reglas de la observación científica; la escala de comparación con las medidas que se hayan tomado, es decir, las leyes de cada país. La centralidad de esta disciplina se debe a que Rousseau como anteriormente Hoocker, Locke y Montesquieu- considera al derecho como "el centro de la vida social, una sociedad sin leyes no es, en último análisis una verdadera comunidad" ${ }^{17}$. A diferencia del despotismo - carente de normas generales y en el que el gobernante ejerce una voluntad autónoma y arbitraria-, su ideal político, la república, es un Estado de derecho basado en la soberanía popular ${ }^{18}$.

En las primeras páginas de El contrato social, Rousseau cuestiona el derecho natural como fundamento de las leyes existentes y se pronuncia por la tesis convencionalista. "El orden social es un derecho sagrado que sirve de base a todos los demás. Sin embargo, este derecho no proviene en modo alguno de la naturaleza, está, pues, basado en las convenciones. Se trata de saber cuáles son esas convenciones" ${ }^{19}$. Examina dos formas de naturalismo: la que sostiene que la fuerza funda el derecho y la que reduce este a una institución familiar.

La tesis de que el derecho se reduce a la fuerza se remonta a los sofistas griegos. Para Calicles existe una contradicción entre las leyes de la naturaleza y las positivas: "por naturaleza es más feo todo lo que es desventajoso, por ejemplo, sufrir injusticia; pero por ley es más feo cometerla. Los que establecen las leyes son los débiles y la multitud mirando su propia utilidad. Es justo que el más fuerte domine al más débil" ${ }^{20}$. La respuesta de Rousseau diferencia claramente entre fuerza y derecho, "la fuerza es un poder físico; no veo qué moralidad podría provenir de su aplicación. Ceder a la fuerza es un acto de prudencia. ¿En qué sentido podrá ser un deber?”21. La fuerza cambia de manos y su desobediencia es legítima. El derecho supone un fundamento moral, crea deber; otorga autoridad que se obedece voluntariamente. Rousseau no consideró los mecanismos de interiorización del poder, de conversión del poder en orden. Opone al concepto de fuerza su concepto del derecho, de carácter democrático y consensual.

Los teóricos del absolutismo consideraban a la organización familiar como micromodelo del Estado absoluto. Robert Filmer escribió a comienzos del siglo XVIII una obra a favor de la doctrina del derecho natural divino de los reyes: Patriarca y el poder natural de los reyes. El nombre de sus capítulos sintetiza su contenido: "I. Los primeros reyes fueron los padres de familia; II. Es antinatural que el pueblo gobierne o

$17 \quad$ Friedrich, Carl J. (1955), La filosofía del derecho, 1980, pp. 181 y 182.

18 Se puede relacionar la concepción absolutista con la del imperium en el derecho romano imperial. Dice Ulpiano que "el pueblo confiere a él (al emperador) y en sus manos todo su imperio y poder” (Cit. por Mondolfo, Rodolfo (1943), Rousseau y la conciencia moderna, p. 79).

19 Rousseau, Jean-Jacques, “Du contrat social...”, OC, tomo III, 1991, p. 352.

20 Platón, Gorgias, 493 d y e, Ed. Clásicos Políticos, Madrid, 1951, p. 59.

21 Rousseau, Jean-Jacques, "Du contrat social...", OC, tomo III, 1991, p. 354. 
elija gobernantes; III. Las leyes positivas no infringen el poder de los reyes"22. Locke dedicó el primero de sus Dos tratados sobre el gobierno civil (1690) a la refutación de las concepciones de Filmer. Rousseau retoma el debate en la línea de Locke. Piensa que la sujeción de los hijos es temporal; terminado su ciclo de desarrollo todos recobran su independencia. La familia podría ser considerada modelo de sociedad política, pues los hijos, habiendo nacido libres e iguales, enajenan su libertad por su propio provecho durante un período.

Otra tesis naturalista funda el derecho en la superioridad natural de los gobernantes o del sector dominante de la sociedad. Aristóteles es mencionado aquí como uno de sus representantes. "Regir y ser regido no sólo son dos cosas necesarias sino convenientes, y ya desde el nacimiento unos seres están destinados a ser regidos y otros a regir. Todos aquéllos que difieren de los demás tanto como el cuerpo del alma o el animal del hombre son esclavos por naturaleza", escribe en su Política ${ }^{23}$. Rousseau cuestiona esta tesis y, en general, la doctrina de la desigualdad natural de los hombres. "Aristóteles tenía razón, pero tomaba el efecto por la causa. Todo hombre nacido en la esclavitud nace para la esclavitud. Los esclavos lo pierden todo con sus cadenas, hasta el deseo de salir de ellas; aman su servidumbre así como los compañeros de Ulises amaban su embrutecimiento. Por tanto, si hay esclavos por naturaleza, es porque hubo esclavos contra naturaleza" 24 .

La relación de dominación, el modo de vida servil, es una relación interna que convierte a unos en señores y a otros en vasallos. Desde la lógica de las apariencias, que solo concibe identidades fijas, los hombres que aparecen como señores o como subordinados siempre han sido lo que son. Su señorío y servidumbre les pertenecen como propiedades naturales. La relación de dominación solo explicitaría lo que siempre ha sido. Hegel, en cambio, mostró que la constitución de la relación señor-vasallo era el resultado de una lucha entre hombres libres y la imposición del poder de unos sobre otros. En el proceso de su relación cada uno llega a ser lo que es; aprende su nueva identidad relacional ${ }^{25}$.

Desde su crítica de las principales formas de naturalismo, Rousseau concluye que el derecho solo puede provenir de las convenciones. "Puesto que ningún hombre tiene autoridad natural sobre su semejante, y que la fuerza no produce ningún derecho, quedan, pues, las convenciones como base de toda autoridad legítima entre los hombres" ${ }^{26}$. La opción de Rousseau por el contractualismo no implica excluir elementos de derecho natural. Consecuentemente, no acepta cualquier forma de contrato social, sino exige que la convención sea justa, conforme al derecho natural, entendido como constitución humana.

Filmer, Robert, Patriarca o el poder natural de los reyes en Filmer, Robert y Locke, John, y Primer libro sobre el gobierno, 1966.

23 Aristóteles, Política, 1254 a y b, 1951, pp. 7 y 8.

24 Rousseau, Jean-Jacques, "Du contrat social", $O C$, tomo III, 1991, p. 353.

25 Hegel, G. La fenomenología del espiritu.

26 Rousseau, Jean-Jacques, "Du contrat social", $O C$, tomo III, 1991, p. 355. 
Seguidamente, examina dos tesis convencionalistas que pretenden justificar el despotismo. La primera se atribuye a Grocio, pero valdría para Hobbes, y sostiene que un pueblo puede enajenar su libertad haciéndose súbdito de un rey. Dice Rousseau: "Enajenar es dar o vender. Un hombre que se hace esclavo no se da, se vende, al menos por su subsistencia; pero un pueblo, ¿por qué se vende?”27. El mantiene al rey, entonces, daría su persona y sus bienes gratuitamente. "Se dirá que el déspota asegura a sus súbditos la tranquilidad civil" ${ }^{28}$. Sin embargo, los déspotas suelen arrastrar sus pueblos a las guerras motivados por su ambición; los privan de sus bienes y los someten a vejaciones. La tranquilidad no es un valor si se obtiene reprimiendo la oposición y la crítica. Podría decirse que los pueblos se dan gratuitamente a sus amos. Pero, este sería un "acto ilegítimo y nulo", una expresión de sin razón y "la locura no hace derecho". Un pueblo que se aliena a sí mismo no podría enajenar las generaciones venideras. Dicha donación excedería los derechos de la paternidad. Por tanto, dicho pacto de sumisión debería ser renovado o anulado en cada generación. El tema es importante, pues para Hobbes y el pensamiento autoritario, el origen de la autoridad es la cesión de la libertad del pueblo en los gobernantes, por tiempo indefinido, y obligatoria para las nuevas generaciones. Al expresar su apoyo o consentimiento el pueblo al poder autoritario, otorgaría legitimidad permanente al orden autoritario, supuestamente fundado sobre ese pacto político.

Para Rousseau, la enajenación de la libertad de un pueblo sería un acto nulo en derecho, pues la libertad es irrenunciable. "Renunciar a la libertad es renunciar a la cualidad de hombre, a los derechos de la humanidad, incluso a sus deberes. No hay ninguna compensación posible para quien renuncia a todo. Semejante renuncia es incompatible con la naturaleza del hombre, y es privar de toda moralidad sus acciones al privar a su voluntad de libertad" 29 . Este texto es cardinal para comprender el pensamiento político de Rousseau. Por una parte, muestra la íntima articulación entre su filosofía del hombre, basada en la libertad como condición humana esencial e irrenunciable; y su filosofía política centrada en la legitimidad democrática. Por otra, marca la ruptura del pensamiento roussoniano con la teoría política del liberalismo clásico, especialmente con Hobbes. Los clásicos liberales consideran inevitable la renuncia completa (Hobbes) o parcial (Locke) de la libertad (política) para constituir la sociedad política. Para ellos, la libertad se escinde en libertad política y libertad económica en y para el mercado. Se sacrifica la primera, "la libertad de los antiguos", para asegurar la segunda, "la libertad de los modernos", como las denomina Constant ${ }^{30}$. Consiguientemente, se subordina la organización política de la sociedad a las necesidades de la sociedad civil, que gira en torno al mercado ${ }^{31}$. La consecuencia sería el empobrecimiento de la política; la

27 Rousseau, Jean-Jacques, “Du contrat social”, $O C$, tomo III, 1991, p. 355.

28 Rousseau, Jean-Jacques, "Du contrat social”, $O C$, tomo III, 1991, p. 355.

29 Ídem, pág. 356.

30 Constant, Benjamín (1957), "De l'esprit de la conquête et de l'usurpation dans leurs rapports avec la civilization européene", Second Partie, cap. VI et VII, en Oeuvres. 
escisión de la sociedad en "lo social” y "político", y la separación del hombre respecto al ciudadano. El texto muestra la radical oposición de Rousseau a todo planteamiento que justifique la desocialización del poder, su concentración en un líder, grupo o clase social.

Frente a las dificultades de fundar la esclavitud o el despotismo en un pacto de sumisión, se ha buscado justificarla como consecuencia de un derecho de guerra: sería una obligación contraída por los vencidos. Aunque Rousseau atribuye esta tesis a Grocio, fue formulada claramente por Hobbes. "Los pactos aceptados por miedo son, en la condición de mera naturaleza, obligatorios. Por ejemplo, si pacto pagar un rescate o servicio por mi vida a un enemigo, quedo por ello obligado, pues es un contrato en que uno recibe el beneficio de la vida y el otro ha de recibir por ello dinero o servicios" ${ }^{32}$. La refutación de Rousseau se dirige a las dos premisas centrales de la tesis: el estado de guerra no otorga derechos sobre los individuos y la guerra no existe en el estado de naturaleza.

Rousseau en El estado de guerra nace del estado social desarrolla sus argumentos. En el estado natural los hombres son pacíficos y tímidos. La valentía es el fruto de la experiencia; las pasiones que lo llevan a la guerra, solo pueden provenir del estado social. La guerra requiere de la asociación. "No hay, pues, ninguna clase de guerra general entre los hombres, y la especie humana no ha sido creada únicamente para destruirse. La guerra es un estado permanente que supone relaciones constantes y estas relaciones rara vez tienen lugar de hombre a hombre" ${ }^{33}$. Es una forma de relación entre Estados; el enemigo es el otro Estado y sus habitantes lo son como soldados o defensores. Solo existe el derecho de matarlos cuando están armados, si se rinden se pierde dicho derecho. El enemigo convertido en esclavo del vencedor no está obligado a obedecerlo salvo si es forzado a ello. La conclusión de este análisis crítico es taxativa: "el derecho de esclavitud es nulo, no sólo porque es ilegítimo, sino porque es absurdo y no significa nada. Estas palabras, esclavitud y derecho se excluyen mutuamente" 34 .

El examen de las doctrinas expuestas constituye una crítica a la teoría política del absolutismo, complementaria a la del Discurso de la desigualdad. Rousseau cree necesario agregar otro argumento diferente. El despotismo no consigue crear una verdadera asociación, ni un cuerpo político: “yo no veo aquí más que un señor y sus esclavos; no veo allí un pueblo y su jefe; es si se quiere una agregación, pero no una asociación ahí no hay bien público, ni cuerpo político" "35. Retengamos los términos de esta oposición. El despotismo solo permite la "agregación" como relación sumatoria de individuos sometidos al gobernante; no hay constitución del "sujeto colectivo", del pueblo. La asociación, en cambio, es una relación horizontal en la que el pueblo

32 Hobbes, Thomas, Leviatán, cap. XIV, pp. 235 y 236.

33 Rousseau, Jean-Jacques, "Que l'état de guerre nait de l'état social” OC, tomo III, 1991, p. 602.

34 Rousseau, Jean-Jacques, "Du contrat social”, $O C$, tomo III, 1991, p. 358.

35 Rousseau, Jean-Jacques, "Du contrat social”, $O C$, tomo III, 1991, p. 359. 
se constituye como "cuerpo político"; he aquí la primera formulación del organismo político de El contrato social. La relación con la democracia se expondrá seguidamente.

Rousseau se propone examinar el acto por el cual el pueblo se hace a sí mismo convirtiéndose en sujeto colectivo. Esto implica la unión de fuerzas de cada uno de sus miembros, dice, "pero siendo la fuerza y la libertad los primeros instrumentos de su conservación ¿cómo las comprometerá sin perjudicarse y descuidar los cuidados que se debe a sí mismo?" 36 . Esto lo define el nuevo pacto social. "Se ha de buscar una nueva forma de asociación que defiende y proteja de toda la fuerza común a la persona y los bienes de cada asociado, y por la cual, uniéndose cada uno a todos, no obedezca, sin embargo, más que a sí mismo y quede tan libre como antes" ${ }^{37}$.

Pareciera una reiteración del contrato social de Locke. Se trataría de crear un tipo de asociación que proteja la seguridad de las personas y sus bienes. Esta lectura ha dado lugar a la interpretación liberal de El contrato social, por la cual el hombre posee derechos inalienables previos al pacto social, diferentes a los "derechos del ciudadano", provenientes de este. En consecuencia, se reconoce frente al Estado un orden privado inviolable al que pertenece la familia, las organizaciones privadas y la vida económica. El "hombre privado" prevalece sobre el "público" o ciudadano ${ }^{38}$.

Asimismo, esta interpretación no percibe la profunda diferencia entre Locke y Rousseau sobre el derecho de propiedad. Para el primero es un derecho natural, que se constituye en la primera fase del estado de naturaleza por la apropiación mediante el trabajo, y en la segunda, por la acumulación y las leyes del mercado. Asimismo, es un derecho ilimitado de acumulación. Para Rousseau, en cambio, es un derecho civil, no previo a la sociedad (política). El contrato social transforma la usurpación precedente en "legítima posesión", convirtiéndola en un "verdadero derecho". Podría decirse que la propiedad garantizada por el contrato social está limitada por el derecho de vida de todos. Debe limitarse la acumulación y enriquecimiento que implica el empobrecimiento para muchos, y la reducción de sus posibilidades o calidad de vida de la mayoría ${ }^{39}$. Para Locke, el derecho de propiedad ilimitada está sobre la vida. Consiguientemente, si alguien quiere despojarme de mi propiedad, tengo derecho no solo a impedirlo sino a matarlo. En Rousseau encontramos una afirmación directa del derecho de vida de todos. "Todos deben vivir", escribe, lo que implica el acceso a los medios de vida y al trabajo, y al derecho $a$ la propiedad y no solo de propiedad.

Rousseau atribuye a la nueva asociación la capacidad de integrar a los ciudadanos, constituyendo "el cuerpo social". Podría pensarse que ha regresado a Hobbes y su idea de la unión real de los ciudadanos en el Estado, no obstante, Rousseau cualifica esta unificación. No significa la pérdida completa de la libertad en aras del Estado, sino al contrario: cada uno no obedecerá más que a sí mismo, puesto que será a la vez miembro

Rousseau, Jean-Jacques, "Du contrat social”, $O C$, tomo III, 1991, p. 360.

Rousseau, Jean-Jacques, "Du contrat social”, $O C$, tomo III, 1991, p. 360.

Aranguren, José Luis (1968), Ética y política, pp. 144 y 145.

Rousseau, Jean-Jacques, “Discours sur l'économie politique”, OC, tomo III, 1991. 
del soberano y del pueblo y "quedará tan libre como antes". Hobbes y Locke buscaban fundamentar la obediencia política a una autoridad externa a los sujetos, pues gobernantes y gobernados eran dos funciones cualitativamente diferentes e incompatibles, y el Estado no podía sino construirse sobre esta escisión. Rousseau cambia los términos del problema, realiza una revolución copernicana de la filosofía política. Concibe un tipo de asociación que hace radicar la soberanía en el pueblo, y con ella la obediencia política sería autoobediencia que preserva la libertad de cada uno.

El proyecto de los teóricos ingleses era crear un Estado de individuos, pues el individuo egoísta y aislado movido por el afán posesivo representa para ellos la culminación del desarrollo humano, el ser humano en su madurez. El Estado es visto como la condición externa, como un medio que posibilita su movimiento y actividad. Rousseau no comparte esta visión del hombre. El individuo moderno no representa para él la plenitud humana, sino solo una forma de existencia humana característica de la sociedad moderna. Es un hombre alterado, fuera de sí y contradictorio. Su ámbito social obstaculiza e impide la realización de su perfectibilidad humana: "siempre en contradicción consigo mismo, fluctuando siempre entre sus inclinaciones y sus deberes, nunca será hombre ni ciudadano; no será bueno para sí ni para los demás. Será un hombre de nuestros días. Ya no existe la institución pública; porque donde no hay patria no puede haber ciudadanos" ${ }^{40}$. Su existencia está traspasada de ambigüedad, vive en la sociedad, pero quiere conservar en ella su condición de hombre natural. "El hombre natural es todo para él, es la unidad numérica, el entero absoluto que no tiene más relación que consigo mismo o con su semejante. El hombre civil es una unidad fraccionaria que determina el denominador, y cuyo valor está en relación con el entero, que es el cuerpo social" 41 . En El contrato social dice que el individuo "es un todo perfecto y solitario".

La institución de un pueblo, la refundación de la sociedad, requiere "cambiar, por así decir, la naturaleza humana" (El contrato social), "desnaturalizar al hombre" (Emilio), para "transformar cada individuo, en parte de un todo mayor, del que el individuo recibe en cierta forma su vida y su ser" (El contrato social); "quitándole su existencia absoluta para darle una relativa, y transportar el yo dentro de la unidad común, de tal manera que cada particular no se crea un entero, sino una parte de esa unidad" $(\text { Emilio })^{42}$. Estas expresiones podrían ser interpretadas como manifestación de un organicismo que disuelve la individualidad en la sociedad. Sin embargo, otros textos demuestran que no niega la individualidad: "por más que los ciudadanos se llaman a sí mismos miembros del Estado, no podrían unirse a él como los verdaderos miembros del cuerpo. Es imposible conseguir que cada uno deje de tener una existencia individual e independiente, gracias a la cual se vale por sí mismo para su conservación" ${ }^{43}$.

40 Rousseau, Jean-Jacques, "Emile”, libro primero, OC, tomo IV, 1990, p. 250.

$41 \quad$ Rousseau, Jean-Jacques, "Emile”, libro primero, OC, tomo IV, 1990, p. 249.

42 Rousseau, Jean-Jacques, "Du contrat social”, $O C$, tomo III, 1991, p. 381, y "Emile”, $O C$, tomo IV, p. 249.

43 Rousseau, Jean-Jacques, “Que l'état de guerre nait de l'état social”, OC, tomo III, 1991, p. 606 . 
Es necesario constituir "un gran tout" que permita superar la fragmentación social y al cual cada uno se integre sin que su individualidad sea anulada como en el Leviatán. Las cláusulas del contrato social se reducen a una: "la enajenación total (l'aliénation total) de cada asociado con todos sus derechos en toda la comunidad" 44 . La diferencia con el pacto hobbesiano es notoria, y define el carácter de la alienación total de cada uno en varios individuos que se convierten en los gobernantes del Leviatán. Para Rousseau, la alienación se realiza en la comunidad. "Cada uno se da entero con sus derechos y la condición es la misma para todos de modo que nadie querrá hacerla onerosa. Esta alienación recíproca debe ser total, pues si quedasen algunos derechos en los asociados, ningún superior podría fallar (prononcer) entre ellos y el público. Siendo cada uno su juez en algún punto, pronto pretendía serlo en todo, subsistiría el estado de naturaleza y la asociación llegaría a ser necesariamente tiránica o vana" ${ }^{45}$.

Este es uno de los aspectos más difíciles de comprender de la filosofía política de Rousseau. Ha sido malentendido, generando interpretaciones arbitrarias. La alienación debe ser total para colocar todos los asociados en un plano de igualdad, para que se integren en una voluntad común equitativa para todos. Las decisiones tomadas en común se aplican a todos, y al estar cada uno sometido a las mismas condiciones que los demás, estas no pueden ser injustas o tiránicas. "Siendo la condición igual para todos, ninguno tiene interés en hacerla onerosa para los demás". La situación en los regímenes autoritarios es completamente diferente: un grupo de poder minoritario toma las decisiones que afectan a todos, pero ellos quedan excluidos de sus efectos. Su interés particular se impone a la sociedad, bajo la apariencia de ser el único y verdadero bien común.

Otra razón que hace que la alienación deba ser total es que si fuera parcial no se constituiría la soberanía como la concibe Rousseau. Si los ciudadanos se reservan derechos privados o presociales, subsistiría un dominio en que existiría un estado natural, el cual podría ampliarse a toda la vida social, tal como ya lo había visto Hobbes. Se ha dicho que en el Leviatán hobbesiano, la guerra de todos contra todos continúa como lucha económica y por el poder. En Rousseau, la relación que cada uno establece con todos no es una dependencia personal, sino un sistema de interdependencia recíproco que favorece a todos. "En suma, al darse cada uno a todos no se da a nadie, y como no hay ningún asociado sobre el cual no se adquiera el mismo derecho que cada uno le otorga sobre sí, se gana el equivalente de todo lo que se pierde, y más fuerza para conservar lo que se tiene" ${ }^{46}$. La posición de Locke es opuesta y estrictamente garantista. El contrato social debe garantizar derechos individuales prepolíticos, especialmente

Rousseau, Jean-Jacques, "Du contrat social”, $O C$, tomo III, 1991, p. 360.

Rousseau, Jean-Jacques, "Du contrat social”, $O C$, tomo III, 1991, p. 361.

Rousseau, Jean-Jacques, "Du contrat social”, OC, tomo III, 1991, p. 361. Rousseau está consciente de que si las diferencias económicas y sociales entre los individuos fueran muy profundas no sería posible que se constituyera este pacto. Por eso, en el Discours sur l'économie politique, estima que deben limitarse las desigualdades económicas. 
el de propiedad. La alienación debe ser parcial, porque dicho derecho es absoluto y jamás debe ser restringido o limitado.

La fórmula del contrato social define el carácter del nuevo estado democrático. "El pacto social (en) su esencia se reduce a los siguientes términos: "cada uno de nosotros pone en común su persona y todo su poder bajo la suprema dirección de la voluntad general; y nosotros recibimos corporativamente (en corps) a cada miembro como parte indivisible e inalienable del todo" 47 .

El término clave es la "voluntad general". El contrato social "produce inmediatamente, en lugar de la persona particular de cada contratante, un cuerpo moral y colectivo compuesto de tantos miembros como votos (voces) (voix) tiene la asamblea, el cual recibe en este mismo acto su unidad, su yo común, su vida y su voluntad" 48 . De este acto de asociación surge un nuevo sujeto: el pueblo, dotado de voluntad general. "Rousseau ha tenido el mérito de establecer como principio del Estado un principio que no sólo según su forma (como por ejemplo, el instinto de sociabilidad, la autoridad divina), sino también según su contenido es pensamiento y en realidad, el pensar mismo: la voluntad", escribe Hegel ${ }^{49}$. Este yo común, la unión, es en sí mismo el fin que permite a los individuos acceder a una vida universal. El Leviatán hobbesiano difiere en rasgos esenciales del pueblo como sujeto moral y colectivo. Es una "persona ficticia", "un ser mecánico", es decir representa las palabras y acciones de otros. "Una multitud se hace una persona cuando son representados por un hombre, siempre que se haya hecho con el consentimiento de cada uno en particular de los de aquella multitud, pues la unidad del mandatario, no la unidad de los representados, lo que hace de la persona una y es el mandatario el portador de la persona, y de una sola persona. La unidad en multitud no puede entenderse de otra forma" ${ }^{50}$. Mondolfo ha destacado que el pacto de sumisión hobbesiano no crea un pueblo sino un Estado autoritario.

Hobbes exige que "todo hombre transfiera todo su poder y toda su fuerza en un solo hombre o clase de hombres, por lo cual todas las voluntades se reduzcan a una sola" ${ }^{51}$. Cada uno forma parte de una multitud consciente en hacerse representar por un mismo sujeto. Esta unidad con el mandatario es la que constituye la unidad del Estado. Cada uno está unido al Estado que lo representa y todos son miembros subordinados de este. Hobbes excluye la posibilidad de que la unidad se forme por relaciones directas entre los sujetos, sin relaciones de representación, como partes de un nuevo todo. La razón no se menciona, pero se deriva de su rechazo a la democracia. Rousseau desarrolla

47 Rousseau, Jean-Jacques, "Du contrat social”, OC, tomo III, 1991, p. 361. Se ha usado aquí la traducción de Salustiano Masó, en Escritos de combate, p. 411. La primera versión de Du contrat social del manuscrito de Ginebra emplea la expresión "inalienable" en vez de "indivisible". Cfr. "Notes et variantes", p. 1446.

48 Rousseau, Jean-Jacques, "Du contrat social", OC, tomo III, 1991, p. 361. La expresión "voix" significa tanto "voces" como "votos".

49 Hegel, Georg W., Principios de filosofia del derecho, p. 285.

$50 \quad$ Hobbes, Thomas, Leviatán, cap. XVI, p. 257.

$51 \quad$ Mondolfo, Rodolfo (1943), Rousseau y la conciencia moderna, 1943, p. 84. 
justamente esta posibilidad negada. La persona pública, el yo común, que surge de la asociación es a la vez el Estado y el pueblo. "Esta persona pública que así se constituye con la unión de todos tomaba el otro tiempo el nombre de ciudad y ahora toma el de República o cuerpo político, el cual es llamado por sus miembros Estado cuando es pasivo, Soberano cuando es activo Respecto a sus asociados, toma colectivamente el nombre de Pueblo" 52 .

El Estado democrático rusoniano es el pueblo convertido en sujeto colectivo que se autogobierna. El acto de asociación le otorga "su unidad, su yo común, su vida y su voluntad". La integración de los individuos al Estado no implica una subsumisión anuladora, subordinación o sumisión, como en Hobbes. Este "cuerpo moral y colectivo" no es el gigante mecánico del Leviatán. Podría entenderse como un todo-de-partes, como dicen los dialécticos, constituido por la relación interna de los ciudadanos entre sí, análoga a la amistad que hace surgir una nueva totalidad que conserva y potencia la individualidad de los sujetos.

Rousseau parece haber redescubierto la idea aristotélica de que la amistad entre los ciudadanos integra la ciudad. "La amistad parece vincular ciudades y podría creerse que los legisladores la toman más a pecho que la justicia. La concordia, en efecto, parece tener cierta semejanza con la amistad, y es a ella a la que las leyes tienden de preferencia, así como, por el contrario, destierran la discordia como la peor enemiga. Donde los hombres son amigos, para nada hace falta la justicia. La más alta forma de justicia parece ser una forma amistosa" ${ }^{53}$. La crítica roussoniana a los efectos de la competencia económica, de la desigualdad, y sus propuestas económicas se orientan a la creación de condiciones de concordancia y "amistad cívica", como la ha denominado Jacques Maritain. El proyecto democrático de Rousseau no se reduce al campo político, requiere de una cultura democrática cimentada en una nueva educación y de una economía política adecuada. Rousseau no quiere reducir las diferentes dimensiones sociales a la política, puesto que posee una clara intuición del carácter integrado del fenómeno social. "La primacía de lo político" en Rousseau podría entenderse de modo análogo que en Aristóteles. Es decir, la política es la ciencia práctica superior porque ella determina las condiciones de las otras formas de práctica social.

La constitución del nuevo "estado ético-político" significa la superación efectiva del hombre natural y el desarrollo de la moralidad y la sociabilidad. "Este tránsito (passage) del estado de naturaleza al civil produce en el hombre un cambio muy notable, sustituyendo en su conducta el instinto por la justicia y dando a sus acciones la moralidad que les faltaba. El hombre que hasta entonces no se había mirado más que a sí mismo, se ve obligado a proceder conforme a otros principios, y consultar su razón antes que escuchar sus inclinaciones (penchants). Sus facultades se ejercitan al desarrollarse, sus ideas se amplían, sus sentimientos se ennoblecen. Lo que el hombre 
pierde por el contrato social es su libertad natural y un derecho ilimitado a todo lo que pueda conseguir. Lo que gana es la libertad civil y la propiedad de todo lo que posee" ${ }^{54}$.

El nuevo "cuerpo moral y colectivo" se denomina "República". Cuando es pasivo, sus miembros le llaman "Estado" y cuando es activo "Soberano", es decir, cuando el pueblo está reunido. Los ciudadanos son miembros del Soberano y a la vez deben respetar sus decisiones. "Cada uno está comprometido con un todo o una colectividad de la cual forma parte, que en el momento del pacto, tenía sólo una existencia virtual" ${ }^{55}$. En Carta a D'Alambert afirma la identidad entre los "soberanos" y "súbditos", que son los mismos ciudadanos en funciones diferentes. Las leyes que el soberano se imponga a sí mismo son todas revocables, incluso el contrato social. Sin embargo, no puede obligarse a nada que se oponga al contrato social que le dio origen, es decir, no puede enajenarse ni siquiera parcialmente ni someterse a otro soberano. El Soberano no puede tener intereses contrarios a los ciudadanos, ni requiere garantía frente a sus súbditos, porque no puede perjudicar a ninguno. Cada individuo puede tener una voluntad particular diferente u opuesta a la voluntad general que tiene como ciudadano, pero no puede desobedecerla porque forma parte de ella. La sujeción a la ley, el Estado de derecho democrático, es el único que libera de toda dependencia personal.

El libro II de El contrato social está dedicado a la soberanía popular, la voluntad general y la ley. Su importancia no es menor que el primero consagrado a la crítica de las doctrinas autoritarias y a definir el carácter fundamental del contrato social. Este Libro muestra, inequívocamente, que el "ideal político" rusoniano es el del Estado de derecho democrático.

La soberanía popular no es más que el ejercicio de la "voluntad general". En el manuscrito de Ginebra escribe: "Hay, pues, en el Estado una fuerza común que lo sostiene, una voluntad general que dirige esta fuerza y es la aplicación de la una en la otra, ésta constituye la soberanía" ${ }^{56}$. Esta no puede enajenarse y el Soberano no puede ser representado. Rousseau no niega que puedan existir concordancias entre una voluntad particular y la voluntad general, pero este acuerdo es inestable, no será "duradero y constante". Ambas formas de voluntad tienen diferencias fundamentales. La voluntad particular "tiende por naturaleza a las preferencias", al interés privado y al bien particular. La voluntad general es la única que puede dirigir el Estado al bien común; tiende a la igualdad, es general frente a los intereses particulares, y solo ella puede realizar el bien público.

Esta distinción cuestiona el supuesto fundamental de la teoría de la representación de Hobbes y Locke: solamente una o varias voluntades particulares conocen el interés general y pueden conducir la sociedad hacia este. Solo ellas poseen la capacidad de representar a todos los ciudadanos, puesto que el pueblo carece de la aptitud de

54 Rousseau, Jean-Jacques, "Du contrat social...", OC, tomo III, 1991, pp. 364 y 365 . Esta cita demuestra la superioridad que Rousseau otorga al estado civil respecto al natural.

55 Derathé, Robert, "Notes et variantes "Du contrat social...” OC, tomo III, 1991, pág. 1447.

56 Rousseau, Jean-Jacques, “Du contrat social...” (1e. version), OC, tomo III, 1991, p. 294. 
autogobernarse. Esta teoría de la representación es una concepción elitista que atribuye exclusivamente a una minoría la capacidad de conocer el interés común y la aptitud política para conducir al pueblo hacia este. Supone que los intereses particulares de dicha elite coinciden con el interés general. Esta teoría de la representación parece ser el correlato filosófico-político de la tesis de la armonía de intereses de Locke y los fisiócratas. Rousseau completa su argumento contra la versión autoritaria de la teoría de la representación señalando: "Si el pueblo promete simplemente obedecer, se disuelve en ese acto y pierde su calidad de pueblo. En el instante en que hay un amo ya no hay soberano, entonces el cuerpo político está destruido" 57 .

Este texto es una importante refutación a la interpretación de Rousseau como un fundador del pensamiento totalitario. Existe una contradicción indudable con el pensamiento nacional-socialista de Adolf Hitler y Carl Schmittt. Dice el primero: "la democracia es el instrumento de la dominación judía. A esta concepción se opone la de la verdadera democracia alemana, el jefe libremente elegido debe reclamar la responsabilidad entera de todas sus acciones. Esta democracia no admite que todos los problemas sean resueltos con el voto de una mayoría. Uno solo decide y enseguida es responsable de su decisión con sus bienes y su vida" ${ }^{2}$. Schmitt diferencia el "Estado legislativo" del "Estado gubernativo". El primero corresponde al Estado de derecho, es un Estado regido por normas impersonales. El derecho se manifiesta como ley y su legitimidad descansa en su legalidad. "En el polo opuesto al Estado legislativo está el Estado gubernativo, que encuentra su expresión característica en la voluntad soberana y el mando autoritario de un jefe de estado que ejerce personalmente el gobierno" 59 . En su concepción del "Estado total del Führer", la unidad política se compone de tres elementos diferenciados pero unidos: el Estado, el partido y el pueblo. El principio integrado es el de la jefatura (Führerprinzip), por el cual el Jefe del partido es Jefe del Estado y del pueblo. El "toma las decisiones políticas decisivas a las que quedan sometidos tanto el Estado como el pueblo, es decir, tanto las estructuras militar, administrativa y judicial como las económicas y sociales" ${ }^{60}$.

En la concepción política rusoniana no hay ninguna figura equivalente a la del Conductor (Duce, Führer o Caudillo), y existe la explícita intención de excluirla. Carl Friedrich y Zbigniew Brzezinski han intentado encontrarla en la figura del legislador de El contrato social. Brzezinski escribe: "Puede demostrarse que el concepto rusoniano de la democracia total se presta fácilmente a degenerar en dictadura total cuando el legislador deja de ser educador y se convierte en gobernante permanente que procede $\mathrm{o}$ intenta proceder a nombre del pueblo" ${ }^{61}$. Para Rousseau, "esa función particular" no es una magistratura, ni soberanía, y el legislador puede ejercer ninguna función gubernativa,

57 Rousseau, Jean-Jacques, "Du contrat social...”, OC, tomo III, 1991.

58 Hitler, Adolfo, Mi doctrina, 1939, p. 15.

$59 \quad$ Schmitt, Carl (1932), Legalidad y legitimidad, 1971, p. 7. 
"quien manda en los hombres, no debe mandar en las leyes, y el que manda en las leyes no debe mandar a los hombres, de lo contrario sus leyes, ministros de sus pasiones, no harían otra cosa que perpetuar sus injusticias, y jamás podría él evitar que visiones particulares alterasen la santidad de su obra" ${ }^{2}$. El legislador solo propone las leyes, el pueblo decide. "El que redacta las leyes no tiene, pues, ni debe tener, ningún derecho legislativo, y el pueblo mismo no puede, aunque quiera, despojarse de ese derecho intransferible" ${ }^{63}$. Podría decirse que, pese a las palabras de Rousseau, el peligro subsiste. Sin duda, muchas concepciones políticas pueden ser usadas como justificación de un régimen autoritario. Esto puede hacerse incluso con la de carácter inequívocamente democrático, contrariando su sentido fundamental. Sin embargo, dicha instrumentalización no transforma el carácter de dicha concepción, ni la convierte en una teoría autoritaria.

La soberanía es indivisible, "es simple y una y no puede dividirse sin destruirse" ${ }^{64}$. Esto se debe a que la voluntad o es general y del cuerpo del pueblo, o es solo la de una parte de él. Rousseau aclara que la soberanía no significa siempre unanimidad, sino que "todas las voces deben ser tenidas en cuenta; toda exclusión formal rompe la generalidad" ${ }^{65}$. Cuestiona la concepción de la división de los poderes del Estado de Locke. La considera una concepción mecánica y agregatoria del soberano. Las distintas funciones son "emanaciones" de la autoridad soberana. Para Rousseau, el poder de legislar es la esencia de la soberanía y debe ser ejercido directamente por el Soberano. Todas las otras formas de poder estatal son "derechos subordinados", incluso el poder ejecutivo. Su ejercicio puede ser confiado a representantes. Esta distinción plantea el problema del carácter de la democracia rusoniana. Su principio es la soberanía popular; la forma de gobierno depende si se delegan o no los "derechos subordinados".

La diferencia entre voluntad general y particular no es suficiente para caracterizar la primera. Ella no debe ser confundida con la "voluntad de todos". "A menudo hay mucha diferencia entre la voluntad de todos y la voluntad general. Esta no tiene en cuenta sino el interés común, y la otra se orienta al interés privado, y es la suma de voluntades particulares, por ello rara vez coinciden. Constituye un signo de decadencia del Estado cuando la voluntad general no es más que la voluntad de todos" ${ }^{\$ 6}$. La voluntad general aparece si en la voluntad de todos quitamos los menos y los más que se anulan entre sí "y queda por suma de las diferencias la voluntad general" ${ }^{67}$. En una nota agrega una diferencia importante. El interés común se forma por oposición a los intereses de cada uno. Podríamos decir que la voluntad general se constituye por oposición a las

62 Rousseau, Jean-Jacques, “Du contrat social...”, OC, tomo III, 1991, p. 382.

63 Rousseau, Jean-Jacques, “Du contrat social...”, $O C$, tomo III, 1991, p. 383.

64 Rousseau, Jean-Jacques, “Du contrat social...”, OC, tomo III, 1991, p. 427.

65 Rousseau, Jean-Jacques, “Du contrat social...”, OC, tomo III, 1991, p. 427.

66 Rousseau, Jean-Jacques, "Du contrat social...”, OC, tomo III, 1991, p. 371. Derathé, Robert opina que "es necesario que la voluntad general, sin embargo, sea al principio la voluntad de todos, sin lo cual no se comprende como al obedecer la voluntad general, los ciudadanos obedezcan "su propia voluntad", p. 1456.

67 Rousseau, Jean-Jacques, “Du contrat social...”, OC, tomo III, 1991, p. 371. 
voluntades particulares, y la voluntad de todos no es más que su agregación. Pero, la relación entre ambas formas de voluntad no aparece clara en estos textos.

Rousseau atribuye a la voluntad general el carácter de siempre recta y siempre tendiente a la utilidad pública, aunque las deliberaciones del pueblo no siempre tengan esas características. "Siempre se quiere el propio bien, pero no siempre se le ve; jamás se corrompe al pueblo, pero a menudo se le engaña, y sólo entonces es cuando parece querer su mal" ${ }^{18}$. El problema no es práctico, pues cada vez que la experiencia muestre que la decisión del pueblo fue adecuada a la utilidad pública, diríamos que se realizó por voluntad general. En caso contrario, diremos que las deliberaciones del pueblo fueron producto del engaño ${ }^{69}$. ¿Por qué atribuye infalibilidad a la voluntad general? Joseph Moreau cree ver en la concepción rusoniana la influencia de Diderot y Malebranche ${ }^{70}$. Para el primero la voluntad general sería como un "acto puro del entendimiento" y poseería la infalibilidad de la intuición cartesiana. Para Malebranche, Dios no actúa a través de voluntades particulares, pues no corresponde a su sabiduría, sino por medio de leyes simples, uniformes y constantes, que son las voluntades generales. La probable inspiración religiosa de esta concepción de la voluntad general correspondería a sus profundas convicciones religiosas expresadas en Emilio $^{71}$.

La formación de la voluntad general requiere que los ciudadanos estén bien informados y deliberen, sin concertarse en grupos de opinión o asociaciones. La voluntad de dichas asociaciones sería general para sus miembros y particular respecto al Estado. La votación, entonces, no expresaría la voluntad de los votantes individuales, sino solo la de las asociaciones. Si una de ellas por su tamaño se impone sobre las demás, entonces desaparecería la voluntad general y regiría una opinión particular. Rousseau piensa que deben impedirse dichas asociaciones. En caso contrario, se debería multiplicar su número para evitar el efecto mencionado. Se produce aquí una ruptura profunda entre el pensamiento político rusoniano y el liberalismo, puesto que el pluralismo político y social es uno de sus principios.

Podemos ahora referirnos a la crítica sobre el "poder absoluto" de la voluntad general sobre los ciudadanos. El Soberano de Rousseau no es un funcionario del Estado, ni tiene el mismo poder del Leviatán hobbesiano, y hay otras diferencias. Primero, Rousseau señala que "además de la persona pública, debemos considerar las personas privadas que lo componen, y cuya vida y libertad son naturalmente independientes de ella"72. En un texto citado decía: "por más que los ciudadanos se llamen a sí mismos

68 Rousseau, Jean-Jacques, "Du contrat social...", $O C$, tomo III, 1991, p. 371.

69 Para Habermas, la voluntad general es una construcción discursiva producto de la formación de consensos mediante proceso comunicativos. Para Hinkelammert los contenidos del bien común se explicitan analizando los efectos destructivos de la aplicación de intereses particulares.

70 Moreau, Joseph (1973), Rousseau y la fundamentación de la democracia, 1977.

71 Ha habido una revalorización de las concepciones metafísicas de Rousseau, criticadas acerbamente por Voltaire y muy valoradas por Kant.

72 Rousseau, Jean-Jacques, “Du contrat social...”, OC, tomo III, 1991, p. 373. 
miembros del Estado no podrán unirse a él como los miembros al cuerpo, es imposible conseguir que cada uno de ellos deje su existencia individual e independiente" 73 . Segundo, lo que cada uno enajena en el contrato social de su poder y sus bienes, de su libertad, es solo una parte que es la que requiere la constitución de la comunidad. El hombre puede disponer libremente de sus bienes y libertad que no estén comprometidos en las convenciones generales. El Soberano es juez de su magnitud. Tercero, este no puede exigir lo innecesario, pues dicha exigencia se haría extensiva a todos los ciudadanos, es decir, a los mismos miembros del Soberano. La obligatoriedad de los compromisos que nos relacionan al cuerpo social proviene de la reciprocidad. El pacto social establece la misma igualdad de derechos para todos. "Un acto de soberanía no es una convención de un superior con el inferior, sino una convención del cuerpo con cada uno de sus miembros" 74 .

La voluntad general no se ejerce "sobre un objeto particular", ni sobre algunos particulares, "la materia sobre la cual se estatuye es general como la voluntad que estatuye". Este acto por el cual "todo el pueblo estatuye sobre todo el pueblo lo llamo una ley" "75. Su generalidad significa que esta se refiere al conjunto de los súbditos y considera sus acciones como abstractas. La soberanía del pueblo consiste en hacer y decidir las leyes que como actos de la voluntad general son indelegables. "Lo que el Soberano ordena sobre un objeto particular no es una ley sino un decreto, no es un acto de soberanía, sino de magistratura" ${ }^{76}$. En este aspecto fundamental, Rousseau es heredero de la idea de Locke del Estado de derecho, pero concibiéndolo de modo diferente.

Para Rousseau la soberanía del pueblo se realiza en la ley, en el marco del Estado de derecho. La legitimidad de la ley exige que el pueblo sea su autor, en el sentido de que decide sobre ellas. Corresponde al ya mencionado legislador proponer las leyes. Rousseau no usa el concepto de Estado de derecho sino el de república. "Llamo República a todo Estado regido por leyes, cualquiera sea su forma de administración (gobierno), porque sólo entonces gobierna el interés público. Todo Gobierno legítimo es republicano, enseguida explicaré lo que es el gobierno"77.

La distinción entre "el principio de gobierno" y "la forma de gobierno" es relevante en su filosofía política. Pero, Rousseau no ha facilitado la comprensión de esta distinción al usar el término "gobierno" y "gobernar" en sentidos diferentes. El enunciado clave es "todo gobierno (gouvernement) legítimo es republicano". Señala en una nota aclaratoria: "no entiendo solamente por esta palabra una aristocracia o una democracia, sino en general todo gobierno guiado por la voluntad general, la cual es la ley. Para ser legítimo no es necesario que el gobierno se confunda con el soberano,

\footnotetext{
73 Rousseau, Jean-Jacques, "Que l'état de guerre nait de l'état social”, $O C$, tomo III, 1991, p. 606 .

74 Rousseau, Jean-Jacques, “Du contrat social...”, OC, tomo III, 1991, p. 375.

75 Rousseau, Jean-Jacques, “Du contrat social...”, $O C$, tomo III, 1991, p. 379.

76 Rousseau, Jean-Jacques, “Du contrat social...”, $O C$, tomo III, 1991, p. 379.

77 Rousseau, Jean-Jacques, “Du contrat social...”, OC, tomo III, 1991, pp. 379 у 380.
} 
sino que sea su ministro; entonces la monarquía misma es república. Esto se aclarará en el libro siguiente" ${ }^{78}$.

En la época de Rousseau la clasificación más usual de los gobiernos era la de monarquía, aristocracia y democracia. Rousseau la conserva y le dedica varios capítulos del libro III. Pero, su preocupación central no es la de las "especies" de gobierno, como les llama, sino los "géneros" o principios legítimos de gobierno. Por una parte, encontramos los gobiernos fundados en diversos principios (la fuerza, un supuesto derecho natural, convenciones de sumisión, etc.) que carecen de legitimidad. Están regidos por voluntades particulares que no pueden alcanzar el interés general. De otra, está la república, basado en el contrato social recíproco por el que se constituye la voluntad general, la que se expresa a través de la ley. Solo ella está orientada por el interés público ${ }^{79}$.

En el Libro II, Rousseau explicita lo que entiende por gobierno en el sentido de administración superior; caracteriza las tres principales formas de este, y muestra su preferencia por una de ellas. En el cuerpo político hay que distinguir la fuerza de la voluntad. La primera constituye el llamado "poder ejecutivo", la segunda es el "poder legislativo". Aunque el pueblo no puede delegar la soberanía, la cual consiste básicamente en la capacidad de legislar, sin embargo, el Soberano puede nombrar ministros que a través de actos particulares hagan cumplir las leyes. "¿Qué es, pues, el gobierno? Un cuerpo intermedio establecido entre los súbditos y el Soberano para su mutua correspondencia, encargado de la ejecución de las leyes, y del mantenimiento de la libertad tanto civil como política" ${ }^{80}$. Los miembros de ese cuerpo se denominan "magistrados" o "gobernantes". Su función "no es más que una comisión, un empleo en el cual no son más que simples oficiales del Soberano, y en su nombre ejercen el poder del que son depositarios, y que él puede limitar, modificar y recuperar cuando lo desee, pues, es incompatible la enajenación de tal derecho con la naturaleza del cuerpo social, y contraria al objetivo de la asociación" ${ }^{\prime 1}$. Hay, claramente, dos sentidos del término "gobierno". En el primero significa el ejercicio de la voluntad general, es decir, soberanía; en esta aceptación "todo gobierno legítimo es republicano". En el segundo, el gobierno es la "suprema administración" y el poder ejecutivo es mandatario del Soberano.

El criterio para diferenciar las especies de gobierno es la relación entre la cantidad de los magistrados y la extensión del pueblo. Se plantean tres posibilidades. La primera, es que el Soberano delegue el gobierno, el poder ejecutivo, a todo el pueblo o la mayor parte del mismo, por tanto, habrá mayor cantidad de magistrados que ciudadanos privados. Esta es la democracia. Otra posibilidad es que los magistrados sean pocos y

Rousseau, Jean-Jacques, “Du contrat social...”, OC, tomo III, 1991, p. 380.

Esta clasificación fue usada por Montesquieu, Charles, El espiritu de las leyes, Libro III. Es una modificación de la de Aristóteles en Política, Libro VI, que diferencia "tres regímenes justos, la monarquía, la aristocracia y la república”, 1289 a 25 a 30, p. 168.

Rousseau, Jean-Jacques, “Du contrat social...”, OC, tomo III, 1991, p. 396.

Rousseau, Jean-Jacques, "Du contrat social...”, OC, tomo III, 1991, p. 396. 
siempre habrá más ciudadanos que ellos. Esta modalidad es la aristocracia. Finalmente, podría haber un solo magistrado. Este es el gobierno real o monarquía.

Rousseau se muestra extremadamente crítico respecto a la forma de gobierno democrático, en el cual el poder legislativo se une al ejecutivo, es decir, el "príncipe", el conjunto de magistrados, es el Soberano. Esta forma correspondería a la "democracia directa". La caracteriza como "un gobierno sin gobierno", donde "el mayor número gobierna y el menor es gobernado". Los asuntos públicos estarían influenciados por los intereses particulares y el pueblo abusaría del gobierno. Finalmente, señala que requeriría condiciones excepcionales: un Estado muy pequeño; pocos ciudadanos que se conozcan entre sí y fueran fáciles de congregar; escasas desigualdades de rango y fortuna; y nada de lujo y sencillez de costumbres. Sería la forma de gobierno más inestable y proclive a "guerras civiles y agitaciones intestinas", pues tendería continuamente a cambiar de forma y exigiría máxima vigilancia y valor para mantenerse. "Si hubiera un pueblo de dioses, se gobernaría democráticamente. Un gobierno tan perfecto no conviene a los hombres" $" 82$.

La opción que nos propone es la del gobierno aristocrático electivo, en lenguaje actual: una democracia semidirecta o participativa, en la cual el poder de legislar es ejercido directamente por el pueblo y el ejecutivo estaría en manos de magistrados elegidos. "Este gobierno limita los magistrados a un pequeño número, y no se convierten en tales sino por elección, medio por el cual la probidad, las luces, la experiencia y todas las demás razones de preferencia y de estimación pública, son otras tantas nuevas garantías de que uno será sabiamente gobernado. En una palabra, es el mejor orden y el más natural que los más sabios gobiernen la multitud, cuando se está seguro de que la gobernarán en provecho de ella y no del suyo en particular" ${ }^{83}$.

\section{Elementos de una interpretación}

"Nadie hizo más que Rousseau para dramatizar la agonía de la fragmentación personal o buscó tan fanáticamente como él los modos de terminarla. Su propósito constante fue encontrar un marco, un orden, en el cual, como lo pone en el Emile "seré yo mismo, sin contradicción, sin división".

Martin Jay ${ }^{84}$

Rousseau es el primer gran crítico del liberalismo clásico inglés y de la Ilustración francesa ${ }^{85}$. Más aun, su obra significó un hito en la historia del pensamiento, pues abrió un amplio espacio teórico desde el que surgió una diversidad de nuevas formas

82 Rousseau, Jean-Jacques, “Du contrat social...”, OC, tomo III, 1991, p. 406.

83 Rousseau, Jean-Jacques, "Du contrat social...”, OC, tomo III, 1991, p. 407.

84 Jay Martin, Marxism and totality (cit. por Benítez, Hermes (1996), "Jean-Jacques Rousseau y su lucha contra la fragmentación”, Estudios Sociales No 89, Santiago, p. 213).

85 Manet, Pierre, Histoire intellectuelle du libéralisme, 1987. 
de pensamiento. Se ha dicho, con una plausible argumentación que fue el fundador del romanticismo ${ }^{86}$, del anarquismo y del socialismo. Realizó la primera crítica profunda del orden social, político y económico de la sociedad moderna en proceso de formación. En ella, planteó, lúcidamente, el problema de la fragmentación social y la necesidad de superarlo, potenciando la dimensión comunitaria de la sociedad ${ }^{87}$. Desde allí, fundó la antropología, según dijo Levi-Strauss y la pedagogía crítica. Puso las bases de la sociología, y Marx, Durkheim y Weber asumieron el análisis sobre la transición entre la sociedad tradicional y la moderna, y la contraposición entre sociedad y comunidad.

Rousseau buscaba potenciar la dimensión comunitaria de la sociedad, mediante la creación de un nuevo orden político y educativo. Fundó una nueva tradición democrática participativa basada en el principio de la soberanía popular, diferente a la de Locke, y su concepción elitista y representativa. Esta supera, a la vez, las limitaciones de la democracia exclusivamente representativa y también de la directa, que no es posible en una sociedad moderna. Dhal, Pateman y otros teóricos de la democracia participativa reconocen a Rousseau como un referente clásico. Asimismo, su concepto de perfectibilidad proporcionó el fundamento para la creación y desenvolvimiento de la corriente del liberalismo del autodesarrollo de John Stuart Mill, John Dewey y otros.

Su pensamiento constituye un cuestionamiento permanente a las teorías elitistas de la democracia, actualmente predominantes, que excluyen o minimizan la participación política permanente. Rousseau ha argumentado, convincentemente, que la democracia republicana no puede reducirse a un método político, a un artificio destinado a asegurar las condiciones políticas de la reproducción de la sociedad de mercado, sino que constituye una forma de vida que concuerda y favorece el desarrollo de las potencialidades humanas ${ }^{88}$. Por ello, no puede reducirse solo al ámbito político; no puede ser verdadera democracia a menos que consiga permear el conjunto de las instituciones públicas y privadas y todas las relaciones sociales. Desde esta perspectiva, el problema de la calidad de la democracia, de ser efectivamente autogobierno del pueblo, no depende solo de la conservación y reproducción de las condiciones del equilibrio político, ni es solo el resultado exitoso de pactos políticos y sociales. Requiere de la constitución y desarrollo de una cultura democrática, de un orden simbólico, que se exprese en la educación, los medios comunicativos, la organización de la cultura y sobre todo en la experiencia cotidiana de todos. La democracia participativa es la organización de la decisión colectiva en un proyecto de "buena vida" para todos, que requiere y favorece una situación de comunidad comunicativa abierta. El imaginario democrático republicano inaugurado por Rousseau continúa siendo el de una comunidad de hombres

Priestley, J. B (1960), Literatura y hombre occidental, cap.10.

Vd. El excelente artículo de Benítez, Hermes, "Jean-Jacques Rousseau y su lucha contra la fragmentación”, 1996.

Dos de los más importantes teóricos de la concepción elitista de la democracia, Schumpeter y Hayek, han explicitado su radical desacuerdo con Rousseau. Vd. Vergara Estévez, Jorge, "La concepción de la democracia de Schumpeter y Hayek", República, liberalismo y democracia, Marcos García de la Huerta, ed., 2011. 
libres e iguales, donde el libre desarrollo de cada uno es condición del libre desarrollo de todos. Sus principios corresponden, según Habermas, a "el contenido normativo de la modernidad", el autodesarrollo, la autonomía y el autogobierno.

\section{Referencias bibliográficas}

Aranguren, José Luis (1968), Ética y política, Madrid: Ed. Guadarrama.

Aristóteles (1951), Política, 1254 a y b. Madrid: Ed. Instituto de Estudios Políticos.

(1954), Ética nicomaquea, México: Ed. Universidad Nacional Autónoma de México.

Benítez, Hermes (1996), “Jean-Jacques Rousseau y su lucha contra la fragmentación”, Estudios Sociales $\mathrm{N}^{\circ} 89$, Santiago.

Brzezinski, Zbigniew (1956), Dictadura totalitaria y autocracia. Buenos Aires: Ed. Libera, 1975.

Constant, Benjamin (1813), "De l'esprit de la conquête et de l'usurpation dans leurs rapports avec la civilization européene", Oeuvres. París: Gallimard, 1957.

Derathé, Robert (1964), "Notes et variantes "Du contrat social", en Jean-Jacques Rousseau Oeuvres complètes, tomo III. París: Gallimard, 1991.

Fijalkowski, Jürgen (1959), La trama ideológica del totalitarismo. Análisis crítico de los componentes ideológicos en la filosofía política de Carl Schmitt. Madrid: Ed. Tecnos, 1966.

Filmer, Robert (1680), Patriarca o el poder natural de los reyes, en F., R. y John Locke, Patriarca o el poder natural de los reyes y Primer libro sobre el gobierno. Madrid: Ed. Inst. de Estudios Políticos, 1966.

Friedrich, Carl J. (1955), La filosofía del derecho. México: Ed. F. C. E., 1980.

Hayek, Friedrich (1960), Los fundamentos de la libertad. Madrid: Unión Editorial, 1978.

Hegel, Georg W. (1807), La fenomenología del espíritu. México: Ed. F. C. E., 1966.

(1821), Principios de filosofía del derecho, Buenos Aires: Ed. Sudamericana.

Hitler, Adolfo (1939), Mi doctrina. Santiago: Ed. Nueva Época.

Hobbes, Thomas (1651), Leviatán. Madrid: Ed. Nacional, 1979.

Jay Martin (1984), Marxism and totality. Berkeley: University of California Press.

Laski, Harold (1939), El liberalismo europeo. México: F. C. E., 1994.

Macpherson, Crawford (1962), La teoría política del individualismo posesivo. Barcelona: Fontanella, 1970.

Manet, Pierre (1987), Histoire intellectuelle du libéralisme. Paris: Hachette.

Mondolfo, Rodolfo (1943), Rousseau y la conciencia moderna. Buenos Aires: Ed. Eudeba, 1962.

Montesquieu, Charles (1748), El espiritu de las leyes. Buenos Aires: Ed. Atenea, 1951. 
Moreau, Joseph (1973), Rousseau y la fundamentación de la democracia. Madrid: Espasa-Calpe, 1977.

Platón (1951), Gorgias. Madrid: Ed. Clásicos Políticos.

Priestley, J. B. (1960), Literatura y hombre occidental. Madrid: Guadarrama.

Rousseau Jean-Jacques (1755), "Discours l'origine...", Oeuvres complètes, tomo III. Paris: Ed. Gallimard, 1991.

(1755), "Discours sur l'économie politique". Oeuvres complètes, tomo III. Paris: Ed. Gallimard, 1991.

(1756-8), “Que l'état de guerre nait de l'état social". Oeuvres complètes, tomo III. Paris: Ed. Gallimard, 1991.

(1762), "Emile o l'education", libro primero, Oeuvres complètes, tomo IV. Paris: Gallimard, 1990.

"Preface" de "Narcisse" en Oeuvres complètes, tomo II. Paris: Ed. Gallimard, 1991.

(1762), "Du contrat social ou Principes de droit politique", Oeuvres complètes, tomo III. Paris: Ed. Gallimard, 1991.

(1764), "Lettres écrites de la montagne", Oeuvres complètes, tomo III. Paris: Ed. Gallimard, 1991.

(1782/1789), "Les confessions", Oeuvres complètes, tomo I. Paris: Ed. Gallimard, 1976.

Escritos de combate. Madrid: Alfaguara, 1979.

Sabine, George (1962), "Las dos tradiciones democráticas", Revista de ciencia política $\mathrm{N}^{\circ}$ 61, Pontificia Universidad Católica, Santiago en http://www7. uc.cl/icp/revista/pdf/rev61/ar6.pdf (Consultado 10.2.2012).

Schmitt, Carl (1932), Legalidad y legitimidad. Madrid: Ed. Aguilar, 1971.

Vergara Estévez, Jorge (2011), "La concepción de la democracia de Schumpeter y Hayek", República, liberalismo y democracia. Marcos García de la Huerta, ed. Santiago: Editorial Lom. 